\title{
Final year M.Pharm. student views and performance in objective structured clinical examinations
}

Jignesh P Patel ${ }^{1,2}$ (D) , Vivian Auyeung ${ }^{1}$ (D), Lynda Cameron ${ }^{1,3}$, Rebecca Chanda $^{1,3}$, Nicola Husain $^{1,4}$, Barry Jubraj $^{1}$, Khilna Shah ${ }^{1,5}$, Rita Shah ${ }^{1,6}$, Niusha Sherikhan ${ }^{1}$, Jennifer M Stevenson ${ }^{1,3}$, Janique Waghorn ${ }^{1}$, Graham Davies ${ }^{1}$

\begin{abstract}
${ }^{1}$ Institute of Pharmaceutical Science, Kings College London, United Kingdom ${ }^{2}$ Depart. of Haematological Medicine, Kings College Hospital, United Kingdom $\quad{ }^{3}$ Depart. of Pharmacy, Guy's and St Thomas' Foundation NHS Trust, London, United Kingdom $\quad{ }^{4}$ Depart. of Pharmacy, Evelina Children's Hospital, Guy's and St Thomas' Foundation NHS Trust, London, United Kingdom ${ }^{5}$ Boots PLC, United Kingdom ${ }^{6}$ Department of Pharmacy, King's College Hospital Foundation NHS Trust, London, United Kingdom
\end{abstract}

\section{Keywords}

Objective Structured Clinical

Examination (OSCE)

Undergraduate Students

Clinical Skills Assessment

Clinical Pharmacy

Correspondence
Jignesh P Patel
Institute of Pharmaceutical Science,
King's College London
Waterloo Bridge Wing
Franklin-Wilkins Building
Stamford Street
London SE1 5RS
United Kingdom
iiq.patel@kcl.ac.uk

\begin{abstract}
Introduction: Objective structured clinical examinations (OSCEs) are widely used as a competency-based assessment of clinical skills within M.Pharm. programmes of many United Kingdom (UK) pharmacy schools. Aim: To evaluate the clinical performance of final year M.Pharm. students and elicit their views and experiences of the OSCE assessment. Methods: Students were divided into 11 groups and completed an OSCE exam, comprising 11 stations of seven minutes in length, following a four-day placement in clinical practice. Students were asked to complete an acceptability questionnaire, and their OSCE performance was correlated with their final degree classification and their Oriel rank position. Results: Overall, the OSCE assessment is acceptable from the students' perspective. Differences were found between the students' performances at the individual OSCE stations. Students performed best on patient consultation stations and least on clinical-problem solving stations. There was no correlation between students OSCE marks and their Oriel rank position. There was however a strong correlation between the students OSCE mark and their final degree classification $(r=0.528, \mathrm{n}=119, p=0.000)$. Conclusion: Final year pharmacy undergraduates perform poorly in activities which demand an element of clinical problem identification. Further research is required on how clinical problem solving skills can be developed amongst undergraduates and the specific role placements have in achieving this.
\end{abstract}

\section{Introduction}

Hepler and Strand defined pharmaceutical care as the responsible provision of drug therapy that aims to achieve definite outcomes that improves a patient's quality of life (Hepler \& Strand, 1990). This seminal paper was a calling card to the healthcare community that with increasing medication use, the incidence of medication related harm was on the rise and there was a real need for care and responsibility around medicines use to be formalised. They proposed that pharmacists were well placed to lead pharmaceutical care and that the profession itself needed to focus its attention away from the product and more towards the patient (Hepler \& Strand, 1990). The role of pharmacists in the United Kingdom (UK) has changed considerably since this publication with pharmacists today fulfilling much of Hepler and Strand's vision: independent prescribing, work in GP practices, the consultant pharmacist role to name a few (Department of Health, 2005; NHS England, 2016; Royal Pharmaceutical Society of Great Britain, 2018).

In response to an increasingly clinically-orientated profession, the General Pharmaceutical Council's (GPhC) curriculum for UK pharmacy undergraduate degrees has included a requirement that undergraduate pharmacy students are exposed to and taught the skills required in practice. Examples of outcomes that students are 
expected to demonstrate at the 'shows how' level of Miller's pyramid (Miller, 1990) include clinically evaluating the appropriateness of prescribed medicines and instructing patients in the safe and effective use of their medicines and devices (GPhC, 2011).

Many UK schools of pharmacy use Objective Structure Clinical Examination (OSCE) assessments in order to assess students' clinical skills and their ability to conduct clinically orientated tasks, so that the third level of Miller's pyramid is assessed. At both the undergraduate and postgraduate level, OSCEs have been proven to be highly effective in assessing clinical competence both within and outside of pharmacy (Harden \& Gleeson, 1979; Rutter, 2001; Crossley et al., 2002; Newble, 2004; Corbo et al., 2006), and are considered a valid, reliable and practical assessment. At King's College London, students in their final year of the Master of Pharmacy (M.Pharm.) degree undertake a module called 'Clinical Decision Making' (CDM). The aim of this module is to prepare students for decision making in complex circumstances, either complex medicines, diseases or patient behaviour, through consideration of the role of science, evidence-based practice and professional aspects such as consultation skills in the identification and resolution of medicationrelated problems. The module currently incorporates a four-day placement within either a primary care (GP practice) or a hospital setting with senior pharmacists working in their clinics or attending ward rounds, building on increasing clinical exposure over the four years of the M.Pharm. programme. Students are assessed in three ways: their knowledge through multiple-choice questions (MCQs); their clinical skills and application of knowledge through the OSCE assessment; and engagement with their placement through a series of portfolio tasks. This breadth of assessment was recently updated from a traditional final written examination paper.

Although OSCES are widely used in many UK pharmacy schools, little work has been published to date evaluating pharmacy undergraduate student's views and acceptability of OSCEs and the relationship between OSCEs and other academic assessments students undertake. The work that does exist shows that pharmacy students find the OSCE assessment helpful in practising the duties required of them during their pre-registration year, acceptable as a means of assessing competence and a fair, taxing and effective form of assessment (McRobbie \& Davies, 1996; Rutter \& Brown, 2002; Corbo et al., 2006).

Following a recent significant change in the CDM module assessment, the authors evaluated the final year M.Pharm. students' performance in their OSCE assessments and their views on their OSCE experience.

\section{Methods}

During the academic year 2017-2018, all final year M.Pharm. students undertook the CDM OSCE assessment during the last week of April 2018. By this time, they had completed their placement (in semester 2) with the OSCES timed to be administered, just prior to their written exams of the other module they complete during the second semester. The OSCE assessment comprised a series of 11 standardised workstations, each of seven minutes in length, drawing on key skills that students were expected to have developed and are desirable, moving into their pre-registration year (Table I). In 'manned' OSCE stations, trained actors were used to play the role of patients and doctors.

Table I: The 11 OSCE workstation categories that students undertook

\begin{tabular}{|c|c|}
\hline $\begin{array}{l}\text { OSCE Workstation } \\
\text { category }\end{array}$ & Description \\
\hline Clinical calculation* & $\begin{array}{l}\text { Student evaluates clinical information provided } \\
\text { and calculate the dosage of a medication, typically } \\
\text { in the context of renal dysfunction }\end{array}$ \\
\hline $\begin{array}{l}\text { Problem identification } \\
\text { and prioritisation* }\end{array}$ & $\begin{array}{l}\text { Student reviews medication chart and asked to } \\
\text { identify and prioritise any problems they identify }\end{array}$ \\
\hline $\begin{array}{l}\text { Pharmacokinetic } \\
\text { calculation* }\end{array}$ & $\begin{array}{l}\text { Student evaluates clinical information on a patient } \\
\text { and calculates pharmacokinetic parameter(s) } \\
\text {-making a dosing recommendation, e.g. loading } \\
\text { dose }\end{array}$ \\
\hline $\begin{array}{l}\text { Problem identification } \\
\text { and resolution* }\end{array}$ & $\begin{array}{l}\text { Student evaluates clinical information provided } \\
\text { and are required to identify any problems and } \\
\text { suggest solutions to the problems identified }\end{array}$ \\
\hline Ethical dilemma* & $\begin{array}{l}\text { Student is provided with a real-world pharmacy } \\
\text { ethical dilemma. They are asked to review the } \\
\text { information and explain the course of action they } \\
\text { would take }\end{array}$ \\
\hline Case based discussion & $\begin{array}{l}\text { Student briefly presents the clinical case they } \\
\text { profiled / reviewed during their placement and an } \\
\text { assessor then questions their understanding of the } \\
\text { therapeutics, pharmacology and pharmacokinetics } \\
\text { aspects relevant to the case }\end{array}$ \\
\hline $\begin{array}{l}\text { Medication } \\
\text { consultation I }\end{array}$ & $\begin{array}{l}\text { Student is asked to consult with a patient who has } \\
\text { newly been prescribed a medication, e.g. } \\
\text { amlodipine for hypertension }\end{array}$ \\
\hline Drug history I & $\begin{array}{l}\text { Students is asked to take a medication history } \\
\text { from a patient and record their findings in the } \\
\text { patient's medical notes }\end{array}$ \\
\hline \begin{tabular}{l|} 
Physician - \\
Pharmacist discussion \\
(problem \\
identification and \\
resolution)
\end{tabular} & $\begin{array}{l}\text { Student is asked to review clinical information on } \\
\text { a patient, identify any problems and then discuss } \\
\text { the resolution of the problem(s) with the patient's } \\
\text { doctor }\end{array}$ \\
\hline $\begin{array}{l}\text { Medication } \\
\text { consultation II }\end{array}$ & $\begin{array}{l}\text { Student is asked to consult with a patient who has } \\
\text { newly been prescribed a medication, e.g. } \\
\text { flucloxacillin for cellulitis }\end{array}$ \\
\hline Drug history II & $\begin{array}{l}\text { Students is asked to take a medication history } \\
\text { from a patient and record their findings in the } \\
\text { patient's medical notes }\end{array}$ \\
\hline
\end{tabular}

*unmanned stations (for manned stations, patients/doctors are simulated by professional actors) 
Students were allocated to groups over three and a half days and each group completed the OSCE assessment over a two-hour period, with the specific content of the stations changing from day to day, but the workstation categories remaining consistent. Following completion of the assessment, a mean mark across all 11 stations was generated to give each student a final OSCE mark which contributed $60 \%$ of the overall module mark.

Due to the significant change in assessment and a shift away from the traditional written exams, students were asked to complete an acceptability questionnaire. This was administered twice: (i) six-weeks prior to the OSCE assessment; and (ii) immediately following the completion of the OSCE, in order to assess the impact, the assessment might have on their own perceived performance. This acceptability questionnaire had two sections, Section 1 was based on Osgood's semantic differential scale, containing 11 bipolar adjectives, on a 7-point rating scale, where 7 represented the positive pole. Section 2 explored students' attitudes and perceptions of the OSCE assessment, on a 5-point Likert scale ( 5 =strongly agree to $1=$ strongly disagree), based on work by Furmedge and colleagues (2016). The purpose of completing a before and after was to evaluate if students' views changed, once they had completed the assessment. For one of Furmedge's questions, the wording was altered to suit the timing of the question: 'My level of anxiety before the OSCE was detrimental to my performance', administered immediately following the OSCE assessment was changed to 'I am worried about the OSCE exam', when administered six weeks prior to the assessment.

During an OSCE briefing session six weeks prior to the assessment, students were additionally asked to report their destination for the their pre-registration, whether they had applied for their pre-registration place through the new Oriel system and if they had, what their Oriel rank position had been. Oriel is the UK wide portal for recruitment to postgraduate medical, dental, public health, healthcare science and pharmacy training programmes. Oriel enables the students to register for pre-registration training, view vacancies, apply, book interviews and assessment centres and manage offers, within a single central location. The new system was introduced in 2018 within the pharmacy pre-registration training sector and aimed to manage the recruitment process for all pre-registration pharmacist hospital training programmes based in England and Wales. Many primary care pharmacist training programmes are also being recruited to through Oriel.

\section{Analysis}

Data from the questionnaires was entered in to Microsoft Excel initially, and then transferred to SPSS version 24 . Descriptive statistics were used to analyse demographic data. Differences between the questionnaire data, six weeks prior to the assessment and immediately after the assessment was compared using paired $t$-test. Correlations between the students' final degree mark and the OSCE performance were explored using Pearson's correlation. The C-statistic was used to represent the final degree mark. This numerical score is generated from the four years of the M.Pharm. degree programme at $\mathrm{KCL}$ and informs the final degree classification; the higher the C-statistic score, the higher the degree classification. This score was also used to explore any correlation between the students Oriel rank position and the final degree classification; significance was set at 0.05 .

\section{Ethical approval}

As this was part of an evaluation of module change, ethical approval was not required.

\section{Results}

During academic year 2017-2018, 123 final year undergraduate M.Pharm. students completed the OSCE assessment. Their mean age was 23.5 years (SD 3.1), with $73 \%(n=90)$ female gender. One hundred and twenty-two students passed the OSCE assessment first time, with one student having to re-sit in August, before graduating.

\section{Student performance}

In this 2017-2018 cohort of students, 44 students graduated with a first-class honours (36\%), 69 students (56\%) with a 2:1, and 6 students (5\%) with a 2:2. At the time of the OSCE assessment, 118 students had provided information on their destination following graduation. Seventy-three (61\%) were going to complete their pre-registration in a pre-dominantly community pharmacy setting, 42 (36\%) were entering hospital pharmacy, 1 (1\%) was going to industry, 2 (2\%) were not undertaking pre-registration training and had made other plans at the time of asking. Of these 118 students, 106 (90\%) had secured their pre-registration application through the new Oriel system, of which 64 could recall or disclosed their Oriel rank position. No correlation existed between students C-statistic score and the Oriel rank position of those students who had provided this information or with their OSCE mark. There was a significant correlation 
between the students OSCE mean mark and the students final degree classification, based on the C-statistic (spearman's correlation, $\mathrm{r}=0.528, \mathrm{n}=119, \mathrm{p}=0.000$ ).

Table II: Mean OSCE mark, according to OSCE station category

\begin{tabular}{lc}
\hline OSCE Workstation category & Mean \% OSCE mark (SD) \\
\hline Medication history II & $93.4(7.8)$ \\
Medication history I & $90.1(9.1)$ \\
Clinical calculation* & $78.9(23.7)$ \\
Medication consultation II & $73.7(13.3)$ \\
Medication consultation I & $71.9(12.9)$ \\
Pharmacokinetic calculation* & $70.9(28.9)$ \\
Case based discussion & $62.8(10.1)$ \\
Ethical dilemma* & $57.8(21.2)$ \\
Physician - Pharmacist discussion & $56.8(15.6)$ \\
Problem identification and prioritisation* & $40.0(22.6)$ \\
Problem identification and resolution* & $37.1(14.7)$ \\
\hline
\end{tabular}

*unmanned stations

Table III: Mean scores six weeks before and immediately following (in bold) the OSCE assessment, based on a 7 point rating scale, where 7 represented the positive pole

\begin{tabular}{|c|c|c|c|}
\hline $\begin{array}{l}\text { Statement six weeks pre- } \\
\text { and immediately post-OSCE }\end{array}$ & Mean (SD) & $t(d f)$ & $p$ \\
\hline Fair & $5.57(1.2)$ & 1.957 (104) & 0.053 \\
\hline Fair & $5.25(1.4)$ & & \\
\hline Practical & $5.78(1.0)$ & $-0.155(106)$ & 0.877 \\
\hline Practical & $5.79(1.1)$ & & \\
\hline Varied & $5.75(1.1)$ & $-1.582(108)$ & 0.117 \\
\hline Varied & $5.95(1.1)$ & & \\
\hline Active & $5.86(1.0)$ & $-1.220(108)$ & 0.225 \\
\hline Active & $6.02(1.1)$ & & \\
\hline Exciting & $4.55(1.4)$ & $-1.189(107)$ & 0.237 \\
\hline Exciting & $4.73(1.3)$ & & \\
\hline Useful & $5.74(1.0)$ & $-0.582(107)$ & 0.562 \\
\hline Useful & $5.81(1.1)$ & & \\
\hline Interesting & $5.26(1.3)$ & $-1.078(106)$ & 0.283 \\
\hline Interesting & $5.42(1.3)$ & & \\
\hline Good & $5.57(1.1)$ & $0.704(104)$ & 0.483 \\
\hline Good & $5.47(1.2)$ & & \\
\hline Taxing & $5.58(1.1)$ & $0.257(105)$ & 0.798 \\
\hline Taxing & $5.55(1.2)$ & & \\
\hline Skills orientated & $5.52(1.3)$ & $-1.759(108)$ & 0.081 \\
\hline Skills orientated & $5.79(1.3)$ & & \\
\hline Effective & $5.56(1.2)$ & $-1.090(108)$ & 0.278 \\
\hline Effective & $5.71(1.1)$ & & \\
\hline
\end{tabular}

Table II provides a breakdown of the mean mark for each OSCE station type. Students performed best on patient interaction stations (medication history and medication consultation stations) and least well on clinical problem solving. The mean module mark for CDM was $68.8 \%$, with the mean OSCE mark of $66.7 \%$. Despite the significant change in module assessment, the mean module mark remained consistent, in keeping with previous years.

Where students were asked to perform patient interaction tasks repeatedly across different stations (medication history taking and medication consultation), a moderate to strong correlation between these stations was found, suggesting that students were able to do these tasks/demonstrate these skills consistently; (Medication History: Pearson's correlation: 0.596, $n=123, p=0.000$, Medication Consultation: Pearson's correlation: 0.407, $\mathrm{n}=123, p=0.000)$.

\section{Student views and acceptability}

Table III provides details of the mean scores to the questions asked in Section 1 of the acceptability questionnaire, six weeks before and immediately after completing the OSCE assessments. No significant differences were found, although the mean score tended to increase positively, immediately after completing the OSCE assessment.

Table IV: Mean scores before and after (in bold) the OSCE assessment, based on a 5 point-Likert scale, where 5 represents 'strongly agree'

\begin{tabular}{|c|c|c|c|}
\hline Question & Mean (SD) & $\begin{array}{c}t \\
\text { (df) }\end{array}$ & $p$ \\
\hline The OSCE will test my progress & $3.95(0.7)$ & 0.913 & 0.363 \\
\hline The OSCE tested my progress & $3.87(0.8)$ & $(108)$ & \\
\hline The OSCE is a worthwhile exercise & $4.06(0.6)$ & 0.862 & 0.391 \\
\hline The OSCE was a worthwhile exercise & $3.98(0.7)$ & $(106)$ & \\
\hline $\begin{array}{l}\text { The OSCE will give me a good chance } \\
\text { to demonstrate my knowledge } \& \text { skills }\end{array}$ & $3.74(0.8)$ & $\begin{array}{c}-0.846 \\
(108)\end{array}$ & 0.400 \\
\hline $\begin{array}{l}\text { The OSCE gave me a chance to } \\
\text { demonstrate my knowledge and skills }\end{array}$ & $3.83(0.9)$ & & \\
\hline The OSCE will be enjoyable & $2.78(1.0)$ & -2.930 & 0.004 \\
\hline The OSCE was enjoyable & $3.11(0.9)$ & $(104)$ & \\
\hline $\begin{array}{l}\text { The OSCE is appropriate to this stage } \\
\text { of the M.Pharm. degree }\end{array}$ & $4.16(0.7)$ & $\begin{array}{c}-1.013 \\
(104)\end{array}$ & 0.314 \\
\hline $\begin{array}{l}\text { The OSCE is appropriate to this stage } \\
\text { of the M.Pharm. degree }\end{array}$ & $4.25(0.7)$ & & \\
\hline The OSCE is acceptable to me & $3.93(0.8)$ & -1.352 & 0.179 \\
\hline The OSCE is acceptable to me & $4.07(0.7)$ & $(105)$ & \\
\hline $\begin{array}{l}\text { The OSCE will balance integration of } \\
\text { clinical skills with basic science }\end{array}$ & $4.00(0.8)$ & $\begin{array}{r}-1.327 \\
(108)\end{array}$ & 0.187 \\
\hline $\begin{array}{l}\text { The OSCE balanced integration of } \\
\text { clinical skills with basic science }\end{array}$ & $4.13(0.8)$ & & \\
\hline
\end{tabular}


Details of the mean scores to the questions asked from Section 2 of the acceptability questionnaire, six weeks before and immediately after completely the OSCE assessments are presented in Table IV.

No significant differences were found between the responses when comparing responses from before to after the OSCE assessment, aside from the question relating to enjoyability, where the mean score significantly rose $(p=0.004)$. When students were asked how worried they were about their OSCE exam, six weeks prior to the assessment, the mean response score was 4.12 (SD 0.9). Following the assessment, when asked about whether their level of anxiety before the OSCE was detrimental to their performance, this question scored a mean response of 3.78 (SD 1.0).

\section{Discussion}

This paper aims to describe the performance of final year M.Pharm. students and their views on the OSCE assessment, following a significant change in the module assessment. The findings suggest that the students found the OSCE assessment acceptable and fair and their overall performance was good. Students tended to perform best in stations which involved patients and where they were tasked to extract or deliver information to a patient. Students performed least well in clinical problem-solving stations, where clinical information had to be assimilated and problems identified and/or resolved, involving a level of decision making by the student.

\section{Student views and acceptability}

The findings from this work resonate with those of Corbo and colleagues (2006) who questioned final year pharmacy undergraduate students using the same Osgood's semantic differential scale. Over two consecutive academic years, the students in Corbo's study rated the 11 adjectives with respect to OSCEs at a median score of 5 or above, aside from the OSCE being described as practical. In the authors' cohort, the students rated these adjectives at a similar level, with mean scores greater than 5 . The only descriptor, which was rated with a score of less than 5 was the exciting adjective (mean score: 4.55 before and 4.73 following the assessment). Perhaps this should not come as a surprise, given the high-stakes nature of the assessment and where the students were in their M.Pharm. journey.

When questioned on their attitudes and perceptions to the assessment, based on questions developed by
Furmedge and colleagues (2016), students gave positive ratings to these statements, with mean scores greater than 3.5 on a 5-point Likert scale, with only one question scoring below this value:' The OSCE will be enjoyable/The OSCE was enjoyable', where this pair of statements scored 2.78 and 3.11 respectively. Interestingly, when questioned about enjoyability, there was a statistically significant shift in the score following completion of the assessment, suggesting that after completion, looking back they actually enjoyed the assessment $(p=0.004)$. The findings also resonate with the findings from Furmedge and colleagues (2016), where Year 1 (Y1) and Year 2 (Y2) medical students' mean scores were comparable to the questionnaire statements, with some in the final year pharmacy group scoring more positively, e.g., The OSCE exam is acceptable to me: 3.93 , versus 3.75 in the $\mathrm{Y} 1$ and Y2 medical students. This may reflect the pharmacy students having had more clinical exposure compared to Y1 and Y2 medical students, and thus giving higher ratings to this statement. It would be interesting to see how final year medical students might rate those statements and how this compares to final year pharmacy students.

Overall, the findings suggest the OSCE is an acceptable form of assessment in the latter years of the M.Pharm. degree, when students have been exposed significantly to the practice environment and the assessment gives them the opportunity to demonstrate their clinical knowledge and skills. This acceptability from the students' perspective may also in part be related to the fact, that students undertake OSCE assessments in the preceding M.Pharm. years at $\mathrm{KCL}$, so have had an opportunity to refine their OSCE technique, by the time they reach the final year of the M.Pharm. Additionally, prior to the OSCE assessment, they receive a briefing on the assessment, explaining the process and what to expect in terms of layout, to help manage any concerns or anxieties they may be harbouring.

The significant change in module assessment does not seem to have had a detrimental effect on student marks or artificially inflating the module mark.

\section{Student performance}

Students appeared to perform well at medication history taking, medication consultations with patients and pharmaceutical calculations stations, where no uncertainty in the final answer existed. They performed less well in stations where they were faced with clinical problems in which they had to identify, prioritise and/or resolve problems and where uncertainty existed and required them to make clinical decisions. They also did not 
score as highly in stations where they had to discuss drug therapy with a prescribing doctor. Perhaps this is unsurprising. In the M.Pharm. degree, skills such as patient consultation, can be delivered within a university classroom setting, through simulation involving the use of patient actors. The art of clinical problem solving and decision making, although can be taught to a certain extent in the university environment through case-based learning for example, this art is refined in the clinical environment. It requires the learner to observe clinical decision making first-hand and then develop their own style through repeated practice. The findings from the students in the study are similar to what has been reported previously. Some 20 years ago, a study assessing pre-registration pharmacists' clinical competence at baseline (McPherson et al., 1999) reported that pre-registration students performed better in information giving stations compared to information retrieval stations. Furthermore, a study of pre-registration pharmacists at the end of their training, who were also assessed through OSCEs reported that students were less likely to fail device counselling or drug history taking stations compared to information retrieval and prescription monitoring stations (McRobbie \& Davies, 1996). These findings from pre-registration students, suggests that even with first-hand exposure of the clinical environment, it takes time to develop the clinical problem-solving skills and decision-making skills required of pharmacists.

Student performance in the problem solving and decision making stations could also be related to the complexity of the task involved. Arguably, consulting with the patient about a single drug treatment or device is easier compared to reviewing a prescription of multiple medications and then identifying the problems and prioritising them and/or resolving them. Perhaps there are too many skills being tested within a single station and OSCE station writers should be mindful of this. A way of overcoming this is to break the different tasks/skills down and have one question/case spanning a number of sequential stations; although those charged with organising the logistics of OSCES will recognise the organisational difficulty with this. The other consideration is one of clinical exposure. Clinical problem solving and decision making requires students to have been exposed to clinical practice, where they observe first-hand clinical problem solving and decision making in action; although the M.Pharm. degree at $\mathrm{KCL}$ provides students with significant clinical exposure through the diet of placements, the question of what is being taken away by the students during these placements arises and whether it is simply enough to place students in the workplace to complete a series of tasks, and how clinical problem solving and decision making is formally built into placement time. More recently, in pharmacy educational circles there is increasing discussion and focus on entrustable professional activities (EPA) (Al-Sallami et al., 2018; Galbraith et al., 2018), which are defined as discrete tasks or responsibilities that a trainee is entrusted to complete and document with appropriate supervision (ten Cate, 2013). EPAs have been used in medical education for some time and are a concept worth exploring in the pharmacy setting, particularly in the context of M.Pharm. placements. Clinical reasoning is a highly desirable skill within a pharmacy graduate but there are many challenges to enable students to think critically including their own perceptions and the fact that thinking is effortful (Persky et al., 2018). Work from the United States suggests that the critical thinking skills of students, as they progress through each year of the curriculum increases year on year by graduation $(p<0.001)$ (Miller, 2003), and thus if the curriculum, including placements are well designed, there is a real opportunity to develop this thread during the undergraduate years. Research and practice suggest several factors that can improve critical thinking and problem solving: a thoughtful learning environment; seeing or hearing what is done to executive cognitive operations that students are trying to improve; and guidance and support of their efforts until they can carry them out on their own (Persky et al., 2018). The authors are now focussing on how problem solving and decision making can be incorporated more into the placements that their students undertake and how to up-skill those being observed in the workplace to overtly role-model these skills in the practice environment. In Corbo's study (2006), the authors suggested that increased clinical exposure was needed to help the student develop their clinical problem solving skills. However, the results suggest that this on its own is not enough; increased time without focus may not lead to the desired outcomes. It's important that time spent on placement by students is time spent well and is made to count. It requires not only the students to engage but those being observed to engage and overtly role-model key skills and when possible to allow the students to practice this skill.

\section{OSCE mark and Oriel}

With many students now required to apply through Oriel for their pre-registration position, the authors assessed whether there was any correlation between their Oriel position and their OSCE mark. Not all students were able to recall or disclosed their Oriel rank position, but for those that did $(n=64)$, there appeared to be no correlation 
(Pearson's correlation $-0.112, \mathrm{n}=64, p=0.378$ ). With the Oriel system using multiple mini-interview (MMI) to discriminate between students, one might anticipate a correlation between OSCE marks and their performance in the Oriel MMI. Further work should be done to explore this with increased experience with the Oriel system, as one might anticipate that those students scoring highly in OSCE assessment do equally as well in $\mathrm{MMI}$ interviews. Interestingly, in this cohort of students, those who performed well in OSCEs also did well in other academic assessments, suggestive of all-round students and their ability to apply their knowledge to the clinical scenarios they were challenged with. Similar findings have also reported by McPherson and colleagues (1999).

\section{What next?}

With increasing OSCE use within the M.Pharm. programmes, and assessment known to drive student learning (Wood, 2009; Wormald et al., 2009), the OSCE assessment provides a real anchor within the M.Pharm. curriculum to highlight to students what is required of them and in many ways can be used as a stick in developing the attributes and skills required of the profession.

$\mathrm{KCL}$ School of Pharmacy now have the OSCE assessment across the four years of the programme, so students know exactly what skills they will be tested on in order to develop to be competent pharmacists, with feedback being built in, so they can refine their skills with continued practice, year on year. Their placement offering is also being reviewed to allow the students to practice these skills when possible in the workplace. The development of key skills does not end when students graduate from college but requires the continued practice of those going into the pre-registration year.

\section{Conclusion}

The criterion-based OSCE is a valid and acceptable high stakes assessment for final year M.Pharm. students. The OSCE allows an assessment of competence and in many ways can be used to drive/focus student learning. At the undergraduate level, students perform best in stations which involve information extraction or delivery to patients. They perform least well in clinical problem solving stations and decision making stations. M.Pharm. placements provide an opportunity to develop problem making and decision making skills and further research is required which demonstrates the optimal manner in which this can be optimised.

\section{Acknowledgments}

The authors extend their thanks to Anjali Patel and Hari Patel, who inputted the raw data into Excel and for their administrative support.

\section{References}

Al-Sallami, H., Anakin, M., Smith, A., Peterson, A., \& Dufull, S. (2018). Experiences in defining Entrustable Professional Activities to drive the learning of undergraduate pharmacy students. Pharmacy Education, 18, 20

Corbo, M., Patel, J.P., Abdel Tawab, R., \& Davies, J.G. (2006). Evaluating clinical skills of undergraduate pharmacy students using objective structured clinical examinations (OSCEs). Pharmacy Education, 6, 53-58. https://doi.org/10.1080/ 15602210500528372

Crossley, J., Humphris, G., \& Jolly, B. (2002). Assessing health professionals. Medical Education, 36, 800-804. https://doi.org/ 10.1046/i.1365-2923.2002.01294.x

Department of Health. (2005). Guidance for the Department of Consultant Pharmacist Posts. Available at: http://www.codeg.org/ fileadmin/codeg/pdf/DH cons pharm.pdf

Furmedge, D.S., Smith, L-J., \& \& Sturrock, A. (2016). Developing doctors: what are the attitudes and perceptions of year 1 and year 2 medical students towards a new integrated formative objective structure clinical examination? BMC Medical Education, 16, 32. https://doi.org/10.1186/s12909-016-0542-3

Galbraith, K., Brock, T., Duncan, G., Hussainy, S., Mak, V., \& Yeap, Y.Y. (2018). Implantation of a health literacy Entrustable Professional Activity for second year pharmacists-in-training on experiential placement. Pharmacy Education, 18, 20

GPhC [General Pharmaceutical Council]. (2011). Future pharmacists Standards for the initial education and training of pharmacists. Available at: www.pharmacyregulation.org

Harden, R.M., \& Gleeson, F.A. (1979). Assessment of clinical competence using objective structured clinical examination (OSCE). Medical Education, 13, 41-54. https://doi.org/10.1111/ j.1365-2923.1979.tb00918.x

Hepler, C.D., \& Strand, L.M. (1990). Opportunities and responsibilities in pharmaceutical care. American Journal of Hospital Pharmacy, 47, 533-543. https://doi.org/10.1093/ajhp/ $\underline{47.3 .533}$

McPherson, G.S., Davies, J.G., \& McRobbie, D. (1999). Pre-registration trainee clinical competence: a baseline assessment. The Pharmaceutical Journal, 263, 168-170

McRobbie, D., \& Davies, G. (1996). Assessing clinical competencea new method of evaluating hospital preregistration trainees. The Pharmaceutical Journal, 256, 908-910

Miller, G.E. (1990). The assessment of clinical skills/competence/ performance. Academic Medicine, 65, S63-7. https://doi.org/ $\underline{10.1097 / 00001888-199009000-00045}$

Miller, D.R. (2003). Longitudal assessment of critical thinking in pharmacy students. American Journal of Pharmaceutical Education, 67, 1-8. https://doi.org/10.5688/aj6704120 
Newble, D. (2004). Techniques for measuring clinical competence: Objective structured clinical examinations. Medical Education, $\mathbf{3 8}$ 199-203. https://doi.org/10.1111/i.1365-2923.2004.01755.x

NHS England. (2016). General Practice - Forward View. Available at: https://www.england.nhs.uk/wp-content/uploads/2016/04/gpfv.pdf

Persky, A.M., Medina, M.S., \& Castleberry, A.N. (2018). A Review of Developing Critical Thinking Skills in Pharmacy Students. American Journal of Pharmaceutical Education, 83(2), 7033. https://doi.org/10.5688/ajpe7033

Royal Pharmaceutical Society of Great Britain. (2018). Pharmacist Independent Prescribers. Available at: https://www.rpharms. com/Portals/0/RPS\%20document\%20library/Open\%20access/Poli cy/GB\%20Prescriber\%20Policy\%20-FINAL.pdf?ver=2018-08-07-15 $\underline{2908-900}$

Rutter, P.M. (2001). The introduction of observed structured clinical examinations (OSCEs) to the M.Pharm degree pathway. Pharmacy Education, 1, 173-180. https://doi.org/10.1080/ $\underline{15602210210345}$

Rutter, P.M., \& Brown, D. (2002). Observed structural clinical examinations: the views of preregistration trainees six month after graduating from Portsmouth University. The International Journal of Pharmacy Practise, 10 (suppl), R48. https://doi.org/10.1111/ j.2042-7174.2002.tb00651.x

Ten Cate, O. (2013). Nuts and Bolts of Entrustable Professional Activities. Journal of Graduate Medical Education, 157-158. https://doi.org/10.4300/JGME-D-12-00380.1

Wood, T. (2009). Assessment not only drives learning, it may also help learning. Medical Education, 43, 5-6. https://doi.org/10.1111/ j.1365-2923.2008.03237.x

Wormald, B.W., Schoeman, S., Somasunderam, A., \& Penn, M. (2009). Assessment Drives Learning: An Unavoidable Truth? Anatomical Sciences Education, 2, 199-2004. https://doi.org/10. 1002/ase.102 